\section{Noise assessment in slaughterhouses by means of a smartphone app}

\author{
Maria Francesca Iulietto, ${ }^{1}$ Paola Sechi, ${ }^{1}$ \\ Clelia Mansi Gaudenzi, ${ }^{1}$ \\ Luca Grispoldi, ${ }^{1}$ \\ Margherita Ceccarelli, ${ }^{1}$ \\ Salvatore Barbera, ${ }^{2}$ \\ Beniamino Terzo Cenci-Goga ${ }^{1}$
}

${ }^{1}$ Department of Veterinary Medicine, University of Perugia; ${ }^{2}$ Department of Agricultural, Forestry and Food Sciences, University of Torino, Italy

\begin{abstract}
Regulation (EC) No. 1099/2009 on the protection of animals at the time of killing establishes an obligation to spare animals any avoidable suffering or stress prior to their slaughter. Although it has been pointed out that stressors also include noise, which can cause suffering and affect the quality of the meat, current legislation does not set a limit for environmental noise in slaughterhouses. This study was conducted in three slaughterhouses in central Italy to assess the environmental acoustic level using a smartphone app. The selected, medium-sized slaughterhouses for pigs and cattle were subjected to measurements using a sound-level meter (Noise Meter for iOS) during working hours at the unloading area and lairage, along the chute to the restraining pen, at the time of stunning and at the slaughter hall. For the bovine lines the average values expressed in $\mathrm{dB}$ ranged from 76.33 (SD 2.08) to 93.00 (SD 2.14) for abattoir 1 , from 75.00 (SD 1.87) to 92.33 (SD 4.89) for abattoir 2 and from 75.67 (SD 7.09) to 88.83 (SD 4.79) for abattoir 3. For the pig lines the average values expressed in $\mathrm{dB}$ ranged from 77.50 (SD 3.11) to 100.33 (SD 1.53) for abattoir 1, from 83.00 (SD 2.00) to 99.75 (SD 2.63) for abattoir 2 and from 71.20 (SD 6.49) to 99.50 (SD 1.31) for abattoir 3. Data show that the pig slaughter line was always noisier than the cattle line and the slaughter hall always showed the highest values (i.e. $100 \mathrm{~dB}$ ), when compared to the unloading area (i.e. $79 \mathrm{~dB}$ ).
\end{abstract}

\section{Introduction}

Audition is the act of hearing a sound in response to acoustic waves or mechanical vibrations acting on a body and the auditory stimuli are the physical stimuli that are a source of sound (Scharine et al., 2009). The response to auditory stimuli is called auditory sensation and depends on the characteristics of the sound itself (intensity, duration, frequency) while the auditory perception involve previous experience and interpretation of the sound (Scharine et al., 2009). Sound frequency is expressed in Hertz: human frequency hearing ranges from $20 \mathrm{~Hz}$ to $20000 \mathrm{~Hz}$, cattle hearing ranges from $25 \mathrm{~Hz}$ to $35000 \mathrm{~Hz}$ and pigs from $42 \mathrm{~Hz}$ to 40 $500 \mathrm{~Hz}$ (Heffner, 1998, Weeks et al., 2009). Everything that exceeds the limits of agreeable sound is defined as noise, that is to say an unpleasant experience for human beings and animals, which can result in a physiological response to adapt to it; it is a non-specific stressor that excites the endocrine system and autonomic nervous system (Brouček, 2014; Manci et al., 1988; Münzel et al., 2017). An increase in noise intensity can lead to stress for both animals and operators subjected to it and scientific literature has described the sound exposures effect on many species in different environment such as zoos, animal shelter, lairages, farms, laboratories (Coppola et al., 2006; Grandin, 2010; Heffner, 1998; Münzel et al., 2017; Orban et al., 2017; Weeks, 2008). The sound intensity is measured in Decibels, which is a logarithmic scale, meaning that $80 \mathrm{~dB}$ is 10 times the intensity of $70 \mathrm{~dB}$. To give an example, $80 \mathrm{~dB}$ is comparable to the noise of a vacuum cleaner at 1 meter, $90 \mathrm{~dB}$ is the noise of a heavy track at 1 meter (Heffner, 1998). It is recommended to use ear protection when the sound level is above $80 \mathrm{~dB}$ and for many decades it has been described that noise can affect human and animals (Wei, 1969).

The silence of the abattoir (Tesei, 2017) may appear to be an oxymoron. However, it constitutes the objective and proof of the optimum application of the correct abattoir management procedures.

Regulation (EC) No. 1099/2009 on the protection of animals at the time of killing clearly establishes the importance of sparing any form of avoidable stress, including also acoustic stress for which, however, no tolerance limits have actually been set. The main sources of stressful noise at the abattoir were identified as the operators' shouting, the metallic noise of slamming the gates and particularly noisy instruments (Berg 2012; Weeks 2008). After the transport, the animals find their arrival at the abattoir to be extremely stressful. Unloading is a delicate operation, which requires adequately trained staff to avoid the use of coercive means and the onset of phenomena of acute stress, with evident repercussions of the quality of the meat (Goumon and Faucinato, 2017; Grandin, 2001). Higher noise levels during unloading and in the lairage affect negatively meat quality (Van De Perre, 2011). After unloading, the animal is channelled into the pen in the lairage, where it will be able to recover before being sent along the chute to the stunning pen, where the processes of stunning and sticking take place (Warriss,
Correspondence: Maria Francesca Iulietto, Dipartimento di Medicina Veterinaria, Laboratorio di Ispezione degli Alimenti di Origine Animale, Università degli Studi di Perugia, via San Costanzo, 06126 Perugia, Italy.

Tel.: +39.075.5857973 - Fax: +39.075.5857976. E-mail: mf.iulietto@gmail.com

Key words: Noise assessment, Abattoir, Animal protection, Decibel.

Acknowledgements: the authors wish to express sincere appreciation to members of Polyglot, Perugia, for a careful reading and comments on the manuscript and to dr. Vito Brozzi form the unit of health and safety in the workplace, University of Perugia, for advices and calibration of the noise meter.

Contributions: BTCG conception, studydesign and coordination of the experiment, CMG data collection, SB, LG and MC analysis and interpretation of data; MFI and PS coordinating the experiment and drafting the article.

Conflict of interests: the authors declare no potential conflict of interests.

Funding: none.

Received for publication: 6 September 2017. Revision received: 26 January 2018.

Accepted for publication: 14 March 2018

This work is licensed under a Creative Commons Attribution-NonCommercial 4.0 International License (CC BY-NC 4.0).

CCopyright M.F. Iulietto et al., 2018

Licensee PAGEPress, Italy

Italian Journal of Food Safety 2018; 7:7053 doi:10.4081/ijfs.2018.7053

2003). Abattoir lairage in fact should represent a quiet place to make animal recover and rest after the transport (Weeks et al., 2009).

Previous studies assessing noise at lairages have shown that vocalisation of cattle and pigs is usually not loud, whereas gates and slammed gates produced a high sound level. In addition, lairages are designed to be easy to clean, with surfaces which reflect, rather than absorb the echo (Weeks et al., 2009). A noisy environment can make all the operations more complex and increase the animals' reluctance (Berg, 2012; Grandin, 2006).

Several tools are used to assess the protection of the animals during slaughtering (checklist, questionnaires, scores) and a visual inspection can reveal the causes of reluctance to move forward, including high environmental sound level (Grandin, 2012; Velarde and Dalmau, 2012). Animal protection is an ethical and regulatory prerequisite and if, on the one hand, consumer awareness has increased, on the other hand, the need for adequate training for the operators has become essential (Sechi 
et al., 2015). We should consider not only the strictly ethical aspect, but also the detrimental effects that conditions of acute and chronic stress have on products of animal origin due to noise-induced cortisol (Van De Perre, 2011). To be precise, it has been highlighted how acoustic stimuli over $85 \mathrm{~dB}$ give rise to PSE (pale soft exudative) carcass quality meat in pigs (Vermeulen et al., 2015). According to Weeks et al., (2009) $80 \mathrm{~dB}$ is considered as an arbitrary limit for animal exposure, since this value is defined as the threshold level for human ear protection for continual exposure.

Sound level meters are useful tool but can be very expensive and require specific knowledge to handle them. Nowadays, sound level meter can be provided by mobile technology with accessible information and can represent a low cost alternative. Since many apps are available for smartphone, accuracy of data based on sound level meter application for the iOS devices, has been compared by several authors. Many researches has been conducted in the recent years evaluating smartphone sound measurements applications (Kardous and Shaw, 2014; Murphy and King, 2016) concluding that certain app can be appropriately used for noise environmental evaluation and that application written for the iOS platform are more precise than those for Android or Windows platforms. In an attempt to evaluate the noise level in three slaughterhouses for cattle and pigs, this paper describes the results of a survey of the levels of sound intensity measured with a smartphone app.

\section{Materials and Methods}

Local Authorities provided a list of abattoirs and from this, a selection was made on the basis of species, throughput, building type and year of construction. Three abattoirs of medium capacity, slaughtering cattle and pigs were selected.

Abattoir 1 slaughters approx. 10,000 cattle and 50,000 pigs per year. The sectors set up for cattle slaughter have eight lairages with cement flooring: five measuring $25 \mathrm{~m}^{2}$ and three $15.6 \mathrm{~m}^{2}$. The lairages are completely under cover inside the building. The chute is $16.5 \mathrm{~m}$ long and $0.8 \mathrm{~m}$ wide. The walkway is level up to the final metre before access to the stunning pen, where it slopes upwards. The stunning pen measures $2.3 \mathrm{~m}$ long and 1 metre wide. There is no dividing wall between the aforementioned sectors. There are ten lairages for the slaughter of pigs, all with cement flooring (two measuring $22 \mathrm{~m}^{2}$, eight measuring 16 $\mathrm{m}^{2}$ ). The chute is $19 \mathrm{~m}$ long and $0.5 \mathrm{~m}$ wide. The walkway is level up to the final stretch, where it slopes upwards with a $90^{\circ}$ curve to the right as far as the entrance to the stunning pen, measuring $1.3 \mathrm{~m}$ in length and $0.5 \mathrm{~m}$ in width.
Abattoir 2 slaughters approx. 2,000 cattle and 20,000 pigs per year. The sectors set up for cattle slaughter has a total of two lairages, each measuring $40 \mathrm{~m}^{2}$, and the floors are made entirely of cement. The pens are completely covered outside the building. The chute is 14 $\mathrm{m}$ long and $1 \mathrm{~m}$ wide. The walkway is level up to the final metre before access to the stunning pen, where it slopes upwards. The stunning pen measures $2.3 \mathrm{~m}$ long and 0.85 metre wide. There is no dividing wall between the aforementioned sectors. The sectors for slaughtering pigs include a total of five lairages, each $6.7 \mathrm{~m}^{2}$, which the animals access via an unloading area measuring $13.5 \mathrm{~m}^{2}$ outside the building, but with protection against inclement weather and raised $0.6 \mathrm{~m}$ above ground level. The chute is $16 \mathrm{~m}$ long and $0.7 \mathrm{~m}$ wide. The floor is made entirely of cement. The walkway is level up to the final stretch, where it slopes upwards with a $90^{\circ}$ curve to the right as far as the entrance to the stunning pen, measuring 1.3 $\mathrm{m}$ in length and $0.5 \mathrm{~m}$ in width.

Abattoir 3 slaughters approx. 6,000 cattle and 10,000 pigs per year. It has a total of seven lairages for cattle, five of which measure 4.9 $\mathrm{m}^{2}$ and one measuring $15.9 \mathrm{~m}^{2}$, all with a cement floor. The pens are located on ground level outside and have protection against inclement weather. The chute is $3.5 \mathrm{~m}$ long and $0.9 \mathrm{~m}$ wide. The walkway slopes upwards all the way. The stunning pen measures $2.4 \mathrm{~m}$ long and $0.8 \mathrm{~m}$ wide. There are four lairages for pig slaughter, varying in size $(16,19,21,31$ $\mathrm{m}^{2}$ ). The animals access the various lairages via an unloading area, measuring $15 \mathrm{~m}^{2}$. The pens have cement flooring and are located outside the building, with protection against inclement weather. The chute is $2.25 \mathrm{~m}$ long and $0.5 \mathrm{~m}$ wide. The walkway slopes upwards without any curves. The stunning pen measures $1.3 \mathrm{~m}$ long and $0.5 \mathrm{~m}$ wide. A wall divides the (external) lairages from the (internal) chute. The survey involved three visits per slaughterhouse per species to three commercial abattoirs of similar throughput and capacity, in Umbria, Italy, for a total of 18 visits. For each visit, 4 rounds of measurements $(30 \mathrm{sec}-$ onds each) every 40-45 minutes were conducted. The following sampling points were selected: i) unloading area (in front of the entrance of the abattoir, on the side of the truck, 3 meters far, data collected during the process of unloading), ii) lairage (in the centre of the lairage area while animal are present and the machineries are turned on), iii) handling to stunning pen (1 meter far from the pathway to pen, when the handling of the animal to be slaughtered started), iv) stunning (on the side of the stunning pen, close to the operator) v) slaughter hall (in the centre of the slaughter hall during the routine activities).

The timeframe of the investigation covered the working day during routine activities.
Data collecting was always conducted by the same professional and with the same smartphone and the same app (Apple iPhone 6 running iOS 10.3.3 and Noise Meter app version $2.3)$ to minimize variability. Noise Meter is used to measure sound level of surroundings and allows real time data recording, customize duration along with measurement frequency and location information. Noise Meter app was set to record maximum, minimum and average $\mathrm{dB}$ values for 30 seconds per sampling point. All measurements were done pointing the microphone towards the area of investigation. All data was exported in .csv format for further processing. A professional sound level meter SVAN 945a (Svantek, Warszawa, Poland) was used for the app calibration. All Noise Meter measurements were in the range $\pm 5 \%$.

The data were statistically treated by analysis of variance (ANOVA): the means were compared by the Fishers Protected Least Significant Difference test at significance level of 0.05 using the Statistical software StatView, 5.0.1 (SAS) for Mac OS 9.

\section{Results}

Table 1 summarises the values for sound intensity in the three abattoirs, divided by species and sampling points. Noise levels expressed in $\mathrm{dB}$ in abattoir 1 ranged from 77.19 (SD 11.283) to 104.65 (SD 4.40), in abattoir 2 from 74.45 (SD 9.81) to 104.69 (SD 3.71) and in abattoir 3 from 69.31 (SD 14.27) to 103.00 (SD 5.35). In particular in the bovine slaughter lines no statistical differences were detected at unloading, lairage, handling to stunning pen and stunning while the slaughter hall in abattoir 3 was statistically significant quieter than abattoir 1 and $2(\mathrm{P}<0.005)$. In the pig slaughter lines lairage in abattoir 2 was noisier than in abattoir 3 and $1(\mathrm{P}<0.005)$, while lairage in abattoir 1 was noisier than in 3 $(>6.3 \mathrm{~dB})$. Handling to the stunning pen in abattoir 1 was statistically significant $(\mathrm{P}<0.005)$. Regarding handling to stunning pen, the lowest values were recorded in abattoir $1(\mathrm{P}<0.005)$. At the stunning statistically significant differences were observed between abattoir 2 and the other two, abattoir 2 being the quieter. The higher peak level was recorded at the pig slaughter line for stunning $(109,00$ $\mathrm{dB}, \mathrm{SD}$ 0.71) and the lowest peak level was recorded during the unloading of bovines of abattoir 1 (54.67, SD 3.51).

In general louder sounds were recorded in pig slaughter line compared to the bovine one.

\section{Discussion}

On the basis of the results obtained, the 
average values in $\mathrm{dB}$ in the various stages show that the pig slaughter line appears to be constantly noisier than the cattle line. The two exceptions were the average measurements obtained in the lairage at abattoir 1 and abattoir 2 , where the noise recorded for the cattle in the lairages was higher.

The unloading stages constantly have a higher sound level for pigs compared to that of cattle. In fact, we have to bear in mind not only the larger number of pigs unloaded simultaneously, but also the vocalisation this species of animal emits under conditions of stress. Van De Perre (2011) recordes values from 69 to 99 $\mathrm{dB}$ during unloading of pigs. In abattoir 2, however, there is greater sound intensity in the lairage of pigs, probably due to the fact that the lairage area for the pigs are adjacent to the chute and near the slaughter hall. This does not occur in the other two abattoirs, where the lairages are further away (in abattoir 1) or even outside the building with a clear dividing wall (in abattoir 3). Weeks et al., (2009) measured the average noise value during the $24 \mathrm{hrs}$ in 34 abattoirs in England and Wales and recorded values from 52 to $79 \mathrm{~dB}$ for cattle lairages and from 46 to $87 \mathrm{~dB}$ in pig lairages. Talling et al.,
(1998) recorded average value of 76-86 dB in pig lairages. Moving on to the chute stage, the average noise levels show constantly higher values for pigs in all three abattoirs. The greatest difference in sound levels between cattle and pigs were detected in abattoir 2 and abattoir 3. Average noise levels obtained in the chute for pigs in abattoir $2(97.1 \mathrm{~dB})$ and abattoir $3(98.4 \mathrm{~dB})$ were much higher than those in abattoir $1(91.5 \mathrm{~dB})$. This could be due to the fact that the pig chute in abattoir 2 is $70 \mathrm{~cm}$ wide (while the chutes at the other slaughterhouses measure $50 \mathrm{~cm}$ ), which frequently enables the animals to move on top of each other as they go forward, resulting in additional stress and vocalisation. Whereas the dividing wall between the chute and the lairages in abattoir 3 is a positive factor for noise at the lairage stage, it probably turns into a negative factor as they advance, as it prevents sound dispersion. The sound levels recorded for the pigs during the stunning stage were also higher compared to those of the cattle. This is due to the very close proximity of the stunning pen, the sticking facility and the machinery used for the initial processing of the pig carcasses. Weeks et al., (2009) measured the average noise value of 34 abattoirs in England and Wales during handling ( 80 to $90 \mathrm{db}$ ), while Van De Perre (2011) recorded levels of 84-95 $\mathrm{dB}$ during the movement to the stunner.

A comparison of the sound levels recorded during stunning in the three abattoirs showed that the average sound level in abattoir 2 during that particular stage is much lower compared to the average values of abattoir 1 (99.40 $\mathrm{dB})$ and abattoir $3(99.50 \mathrm{~dB})$, even though the average noise levels measured at abattoir 2 during unloading, lairage and the chute are higher than or very similar to those of the other two abattoirs. In the processing area, the average noise levels are clearly far higher in the pig slaughter line, as a result of the structural proximity of the stunning pen and sticking facility and the machinery for the initial processing of the pig carcasses. There were no differences between the processing areas of the slaughterhouses as regards pigs.

Details of the cattle slaughter line showed the average values obtained for the unloading, lairage and the chute stages were basically similar in all three structures under examination.

In abattoir 3, the average noise levels in the stunning pen and in the slaughter hall were far

Table 1. Average values expressed in $\mathrm{dB}$ in three abattoirs in Central Italy.

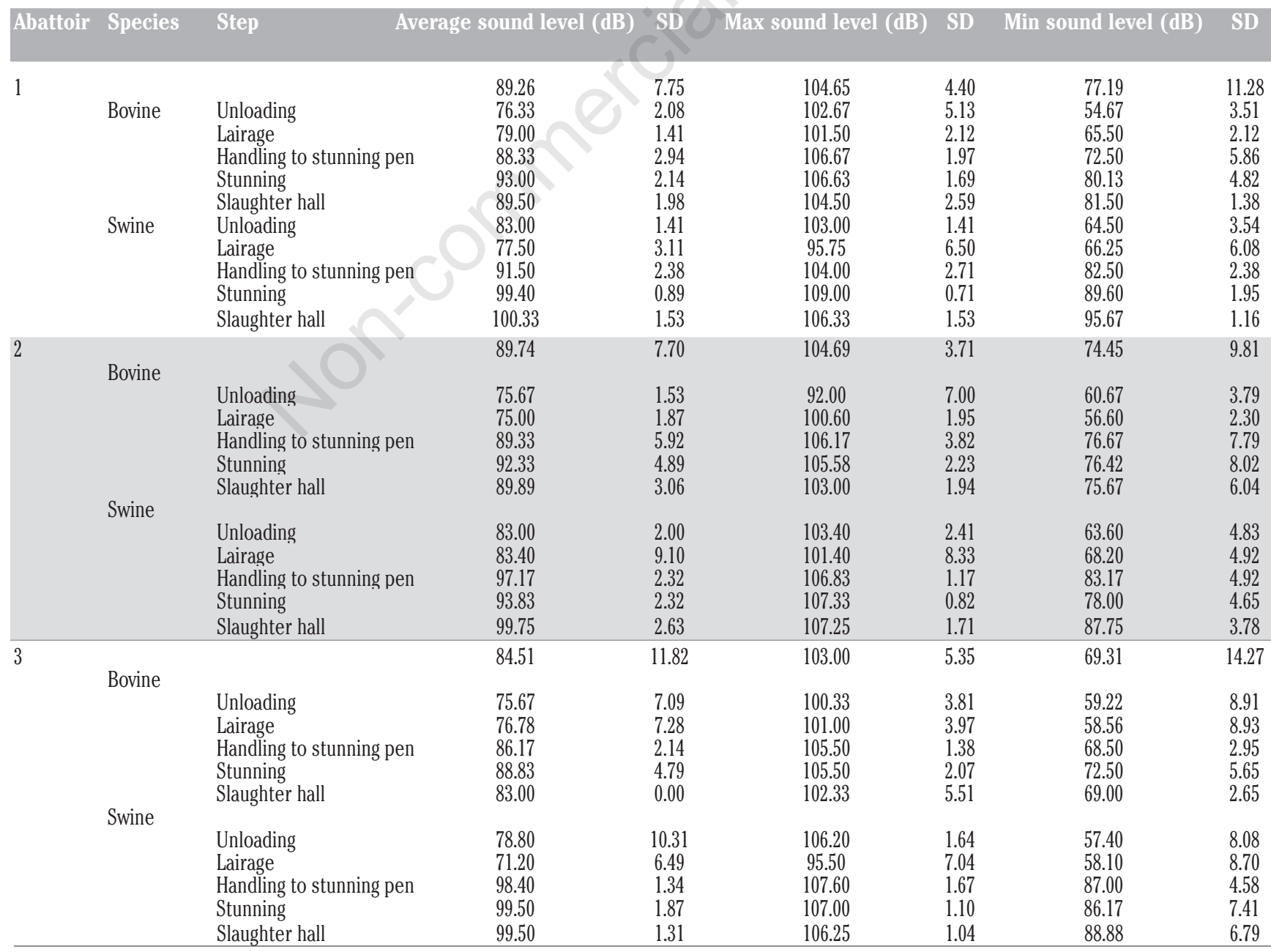


lower compared to the other two slaughterhouses. In fact, the average noise values for the bovine slaughter line of abattoir 3 were 88.83 $\mathrm{dB}$ during stunning and $83.00 \mathrm{~dB}$ for the slaughter hall, whereas in abattoir 1 they were $93.00 \mathrm{~dB}$ during stunning and $89.50 \mathrm{~dB}$ for the slaughter hall and at abattoir 2 they were 92.33 $\mathrm{dB}$ during stunning and $89.89 \mathrm{~dB}$ in the slaughter hall. We should also take into account that the cattle stunning pen at the latter slaughterhouse lies close to the external area (where the lairages are to be found) and this could create a greater dispersion of sound. The noise effect regards animals to be slaughtered and it is associated to a condition of stress before slaughtering but also for the employers who rarely use hearing protections (Coppola et al., 2006).

\section{Conclusions}

This study focuses its attention on one particular aspect, which can contribute to achieve more effective animal protection and a possible improvement of the European law to ensure compliance with the noise limits, in fact it is important to address any stress-inducing stimuli that can be reduced or eliminated. Without regulation on noise level, noise will be completely operator-dependent with higher risk of reduced protection of the animals. As suggested by Van de Perre (2011), building slaughterhouses with sound isolation or reflective materials or with a decibel alarm could prevent losses in meat quality.

The different layout of the lairage areas, the animals/hours and trained personnel all influence the environmental noise level. The abattoirs carried out similar activities and data was compared according to the species in the same abattoir and between abattoirs. All three slaughterhouses revealed that the noisiest part is the slaughter hall, where all the machinery stands, and the pig line is noisier compared to the cattle line. By comparison, the abattoir with the lairage area physically separated from the remaining areas is the least noisy. Each species showed substantial differences. In general, the sounds were louder in the case of pig slaughtering, with a peak value of $109.00 \mathrm{~dB}$ at the stunning area of abattoir 1. Recordings over $80 \mathrm{~dB}$ were very common during morning activities, when the abattoirs were busy and people are advised to wear ear defenders when exposed to levels above $80 \mathrm{~dB}$. Our conclusions, therefore, highlight that in all the abattoirs visited, the noise levels recorded during working hours are high, especially during the chute and stunning stages, which actually require the handling of the animals. Structural interventions to reduce the noise levels do not appear easy to implement in the buildings we visited. However, these, together with the materials and machinery, should be taken into consideration, if new abattoirs are to be constructed.

Adequate training for staff in charge of slaughter is of fundamental importance, as the correct practices of handling and management of the animals enables the general noise level and the correlated stress of the animals to be contained. Lastly, we must remember that the sound levels recorded are also potentially harmful for man. In this specific sector regarding animal slaughter, as in other work sectors, investigations into environmental noise is essential, in order to opportunely prevent occupational illnesses linked to acoustic pollution in the workplace. As a result, our remarks obtained by a smartphone application were able to describe and compare the sound levels during the operational stages of three slaughterhouses and could serve to improve protection of animal and human health from noiseinduced stress.

\section{References}

Anonymous, 2009. Council regulation ec no 1099/2009 of 24 september 2009 on the protection of animals at the time of killing.

Berg C, 2012. Monitoring animal welfare at slaughterhouses. In: Sustainable agriculture. Uppsala p. 349-351.

Brouček J, 2014. Effect of noise on performance, stress and behavior of animals Slovak J Anim Sci 47:111-23.

Coppola CL, Enns RM, Grandin T, 2006. Noise in the animal shelter environment: Building design and the effects of daily noise exposure. J Appl Anim Welfare Sci 9:1-7.

Goumon S, Faucinato L, 2017. Influence of loading handling and facilities on the subsequent response to pre-slaughter stress in pigs. Livestock Sci 200:6-13.

Grandin T, 2001. Cattle vocalizations are associated with handling and equipment problems at beef slaughter plants. Appl Anim Behav Sci 71:191-201.

Grandin T, 2006. Progress and challenges in animal handling and slaughter in the U.S. Appl Anim Behav Sci 100:129-39.

Grandin T, 2010. Auditing animal welfare at slaughter plants. Meat Science.86:56-65.

Grandin T, 2012. Auditing animal welfare and making practical improvements in beef-, pork- and sheep-slaughter plants. Anim Welfare 21:29-34.

Heffner HE, 1998. Auditory awareness. Appl Anim Behav Sci 57:259-68.

Kardous CA, Shaw PB. 2014. Evaluation of smartphone sound measurement applications. J Acoustical Soc Am 135.

Manci KM, Gladwin DN, Villella R, Cavendish MG, 1988. Effect of aircraft noise and sonic booms on domestic animals and wildlife: A literature synthesis.
Fort Collins, CO.

Münzel T, Daiber A, Steven S, Tran LP, Ullmann E, Kossmann S, Schmidt FP, Oelze M, Xia N, Li H, 2017. Effects of noise on vascular function, oxidative stress, and inflammation: Mechanistic insight from studies in mice. European Heart J 0:1-12.

Murphy E, King EA, 2016. Testing the accuracy of smartphones and sound level meter applications for measuring environmental noise. Appl Acoustics 106:16-22.

Orban DA, Soltis J, Perkins L, Mellen JD, 2017. Sound at the zoo: Using animal monitoring, sound measurement, and noise reduction in zoo animal management. Zoo Biol 36:231-6.

Scharine A, Cave KD, Letowski T, 2009. Auditory perception and cognitive performance In: Helmet-mounted displays : Sensation, perception, and cognition issues. Fort Rucker, Ala.

Sechi P, Baldinelli C, Iulietto MF, Goga BT, 2015. Animal welfare: Data from an online consultation. Ital J Food Safety 4:230-4

Talling JC, Lines JA, Wathes CM, Waran NK, 1998. The acoustic environment of the domestic pig. J Agricult Engin Res 71:112.

Tesei E, 2017. Veterinary at the ass4, Italy.

Van de Perre V, 2011. Evaluation of pigs' welfare and meat quality in relation to housing, transport and slaughterhouse procedures Belgium: Katholieke Universiteit Leuven.

Velarde A, Dalmau A, 2012. Animal welfare assessment at slaughter in europe: Moving from inputs to outputs. Meat Sci 92:24451.

Vermeulen L, Van de Perre V, Permentier L, De Bie S, Verbeke G, Geers R, 2015. Sound levels above $85 \mathrm{db}$ pre-slaughter influence pork quality. Meat Sci 100:26974.

Warriss P, 2003. Optimal lairage times and conditions for slaughter pigs: A review. D - 0031164.153:170 -6.

Weeks CA, 2008. A review of welfare in cattle, sheep and pig lairages, with emphasis on stocking rates, ventilation and noise. Animal Welfare 17:275-84.

Weeks CA, Brown SN, Warriss PD, Lane S, Heasman L, Benson T, 2009. Noise levels in lairages for cattle, sheep and pigs in abattoirs in england and wales. Vet Record 165:308-14.

Wei BL, 1969. Physiological effects of audible sound: Aaas symposium, 28-30 december 1969, Boston. Science 166:533-5. 